\title{
Assessment of low level diode laser therapy versus arthrocentesis in management of temporomandibular joint internal derangement
}

\author{
Original \\ Article
}

\author{
Adullah Atef Hammuda \\ Department of Oral and Maxillofacial Surgery, Faculty of Dentistry, Minia University, \\ Minia, Egypt
}

\begin{abstract}
Introduction: Many nonsurgical therapies have been suggested for the management of Disc derangement disorders such as physical therapy, pharmacologic therapy, through psychological counselling, cognitive behavioural therapy, occlusal splints and acupuncture. Among physical therapy procedures, low level laser therapy (LLLT) has recently been proposed to reduce symptoms and improve function in TMD patients.

Aim: The aim of this study is to evaluate effectiveness of Low level diode laser therapy as a treatment modality in temporomandibular joint internal derangement.

Patients/Methods: Thirty six patients presented with jaw pain, clicking and limited mouth openings were involved in this study. Clinical, radiographic and magnetic resonance imaging (MRI) were performed to exclude muscular, hyperplastic or degenerative causes. They were divided randomly into two groups. group I, subjected to arthrocentesis and group II, subjected to ten sessions of LLLT on fixed predetermined points.

Results: Statistical analysis has shown a significant improvement in both groups after six month regarding Pain, range of mandibular movements and clicking. In comparison between both groups the change in maximal mouth opening (MMO) and clicking was higher in arthrocentesis group than LLLT group.
\end{abstract}

Key Words: Arthrocentesis, diode laser therapy, temporomandibular joint

Received:23 July 2018, Accepted:01 August 2018

Corresponding Author: Dr. Adullah Atef Hammuda, Department of Oral and Maxillofacial Surgery, Minia University, Minia, Egypt, Tel.: +20 1062318895, E-mail: dr.abdullahatef@gmail.com

ISSN: 2090-097X, May 2018, Vol. 9, No. 2

\section{INTRODUCTION}

Internal disc derangement (ID) of temporomandibular joint TMJ is a disturbance in normal anatomic relationship between the intra-articular disc and condyle resulting in interference in smooth movement of the joint 1 . TMJ ID is considered a progressive disorder as it starts usually as clicking associated with normal opening (anterior disc displacement with reduction), to a stage where clicking gradually ceases but restricted mouth opening ensues (closed lock). ${ }^{[2]}$

Many nonsurgical therapies have been suggested to be the most effective way of managing over $80 \%$ of patients. Physical therapy, pharmacologic therapy, through psychological counseling, cognitive behavioral therapy, occlusal splints and acupuncture are considered different treatment modalities in treating TMJ ID. The main objective of all these treatment modalities is to reduce the symptom intensity, thereby improving the function of masticatory system and adjacent structures. ${ }^{[3,4]}$

Physical therapy is effective for individuals who may have pain in their musculature. Although physical therapy produces short term relief of signs and symptoms, there is little evidence suggesting that it produces a long term reduction in signs and symptoms of temporomandibular disorders. ${ }^{[5,6]}$

Arthrocentesis of the temporomandibular joint has been described as the simplest form of surgery in the TMJ. Arthrocentesis has been reported to reduce joint pain, improve function, and reduce clicking. It releases the articular disc from adhesions between its surface and the glenoid fossa by means of hydraulic pressure from irrigation of the upper chamber of the TMJ. ${ }^{[7,8,9]}$

Laser is the acronym for light amplification by stimulated emission of radiation. Laser can be classified based on power into 3 categories: High power laser which increases tissue kinetic energy and uses output power of more than $500 \mathrm{~mW}$, Intermediate power laser which uses output power of $250-500 \mathrm{~mW}$ and low power laser which have no thermal effect on tissues and uses power of less than $250 \mathrm{~mW}^{[10]}$.Low-level laser therapy (LLLT) has been suggested to have biostimulating and analgesic effects through direct irradiation without causing thermal response. The primary mechanisms of therapeutic laser were mainly referred to the interaction between photons and cell molecules that transform the photonic light 
energy into biochemical energy, whereas the secondary mechanisms were referred to chemical changes induced by the primary effects. The photochemical effect occurs when the laser light is emitted at low power for prolonged periods of time, and is dependent upon the wavelength, dose, and mode of operation ${ }^{[11,12]}$. It was reported that LLLT also raises cell activity and adenosine triphosphate (ATP) production. It also increases release of growth factors, cytokines, and accelerates replication mechanisms that result in promotion in cell repair processes and declines the oxidative phase. Laser light can also react with beta growth factors and many different oxygenated molecules. These reactions indicate the biostimulation effect of therapeutic laser ${ }^{[13]}$. The analgesic effect of Low level Laser radiation has correlation with the increase of beta endorphin in cerebrospinal fluid and normalization of the telethermographic state of the inflamed tissue ${ }^{[14]}$. LLT increases blood flow and induces angiogenesis as it increases lymph drainage and consequently inflammation decreases. It has an efficient antiedemic action that encourages early drainage of the interstitial fluid because of increased lymphatic peristalsis. Furthermore; the biochemical effect of the laser light can stimulate the production of vascular endothelial growth factor and the conversion of adenosine-monophosphatase into nitric oxide, which improves vessel growth. ${ }^{[15]}$

Biological actions of LLLT, easy application, limited treatment time and minimum contraindications render it a good option for the treatment of musculoskeletal disorders. Many reports were published on the clinical efficacy of LLLT for the treatment of temporomandibular joint disorders due to its analgesic, anti-inflammatory and regenerative effects. However the variation in methodology, dosimetry and other parameters between studies, and the inclusion criteria and diagnosis of the patients, the studies are not standardized and consequently the results differ and comparison is difficult. ${ }^{[16,17]}$

In this study, diagnosis was based in accordance with the Research Diagnostic Criteria for Temporomandibular disorders (RCD/TMD) proposed by Dworkin and Le Reserche18 to evaluate effectiveness of Low level diode laser therapy as a treatment modality in temporomandibular joint internal derangement in comparison with Arthrocentesis which is considered an evident treatment modality for a such disorder.

\section{MATERIALS AND METHODS}

In this study, thirty six patients were selected according to RDC/TMD, Axis 1 group II a. They were presented with jaw pain, clicking or limited mouth opening were involved in this study. Clinical, radiographic and magnetic resonance imaging (MRI) were performed to exclude muscular, hyperplastic or degenerative causes. They were divided randomly into two groups. group I( arthrocentesis group ) included 17 patients , and group II, (LLLT group) included 19 patients subjected to ten sessions of LLLT on fixed predetermined points.

All patients didn't receive splint therapy at least three months before procedures and they also didn't receive any NSAIDs for two weeks before and during treatment procedures. Joint pain was evaluated during maximal mouth opening on a visual analogue scale (VAS) with endpoints 0 score for no pain and 10 score for the worst pain experienced. All patients were asked to place a mark on the VAS line to represent their intensity of pain during joint function. Maximal Mouth opening (MMO) was measured inter-incisally with a millimeter caliper as a mean of both assisted \& unassisted mouth opening measures. Assisted mouth opening was measured after applying gentle pressure reaching maximal mouth opening. All measures were recorded immediate postoperative, then one week, two weeks, four weeks, three months and six months.

All Patients were informed about the procedure, complications; the materials used and follow up appointments. A signed written consent was obtained from the patients before the procedure.

\section{Group I (Arthrocentesis group):}

Arthrocentesis was performed in the outpatient clinic under local anaesthesia. The operative site was prepared aseptically and the area was isolated with sterile drapes. Entry points were marked along the canthotragal line. The first point corresponding to glenoid fossa was marked 10 $\mathrm{mm}$ from the midtragus and $2 \mathrm{~mm}$ below the line and second point corresponding to articular eminence was marked 10 $\mathrm{mm}$ from the first point and $10 \mathrm{~mm}$ below the line. A 20 gauge needle was then introduced at the first point and $2 \mathrm{ml}$ of saline was injected through this needle to distend the joint space. Another 20 gauge needle was then inserted at the second point to establish a free flow of the solution through the joint space. A syringe filled with saline was injected under pressure into the superior joint space through the first needle and second needle provided the outflow for the saline. The upper joint compartment was irrigated with 100 to $200 \mathrm{ml}$ of sterile saline solution, allowing a free flow. Patient's lower jaw was gently manipulated in the vertical, protrusive and lateral excursions to free up the disc.

\section{Group II, (LLLT group):}

All patients in this group received ten session of laser application on a three certain points. Each point is circular and $8 \mathrm{~mm}$ in diameter. They were predetermined for all patients as the following:

(1) lateral pole of the condyle during rest position as shown in Fig.1.

(2) the point posterior to the lateral pole at maximum opening as shown in Fig. 2.

(3) Posterior aspect of the condyle from the external 
auditory meatus as shown in Fig. 3. Each session is six minutes divided on three points 2 minutes for each point with laser beam $(870 \mathrm{~nm}$ wavelength in continuous mode at $75 \mathrm{~mW}$ ).

The LLLT device used in the study was a diode laser. Data presented as mean, standard deviation (SD) for pain score and MMO, and Percentage for clicking. Data explored for normality using Kolmogorov-Smirnov and Shapiro-Wilk tests. Chi-square test used to compare between different group for Gender distribution, Clicking and VAS. Wilcoxon signed rank test used to compared between preoperative evaluation and each follow-up periods for VAS

Independent t-test used to compare between tested groups for age and MMO (mm). Dependent t-test used to compare between preoperative evaluation and each followup periods for MMO. The significance level was set at $P \leq 0.05$. Statistical analysis was performed with IBM ${ }^{\circledR}$ SPSS ${ }^{\circledR}$ Statistics Version 22 for Windows.

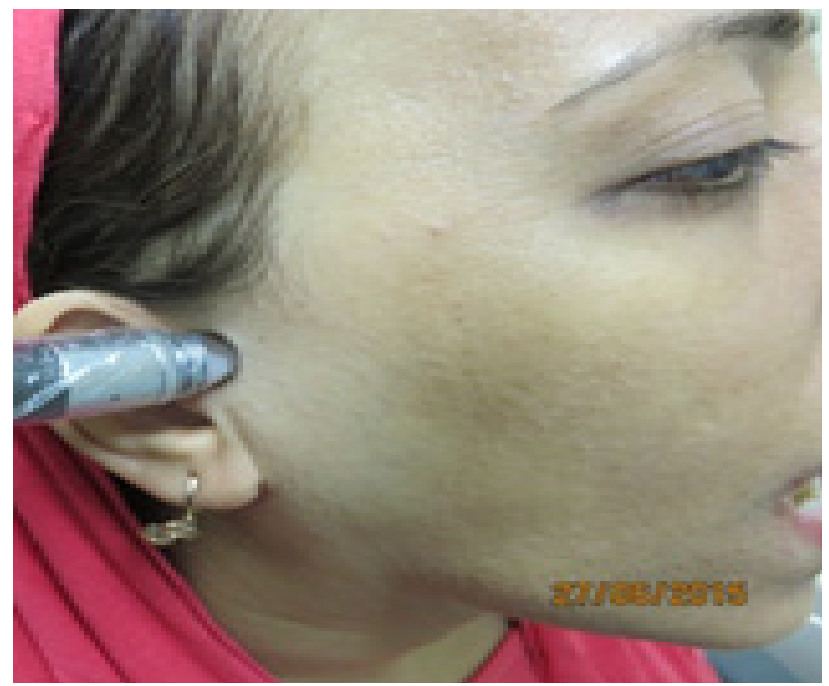

Fig 1: Application of laser probe on lateral pole of the condyle at maximum mouth opening

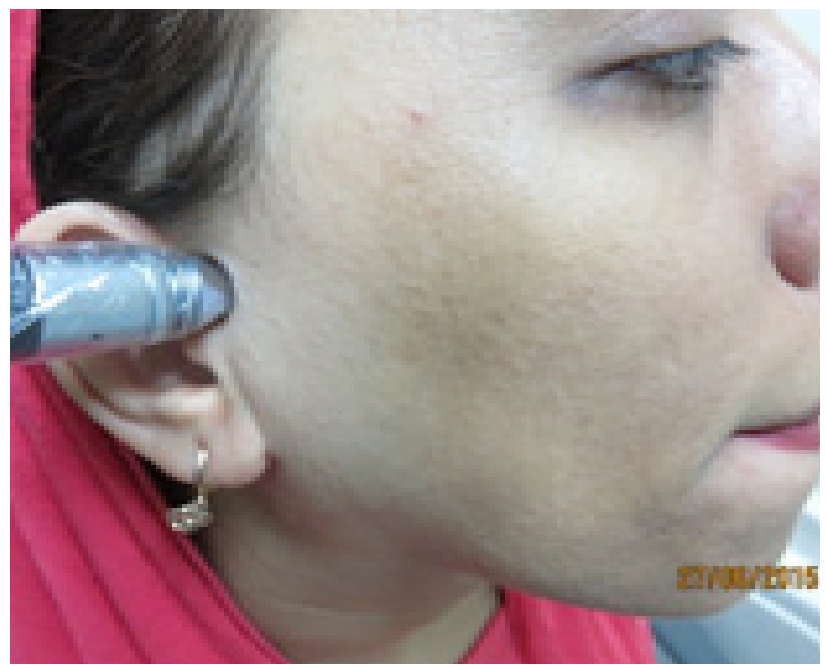

Fig 2: Application of laser probe on the point posterior to the lateral pole at rest position

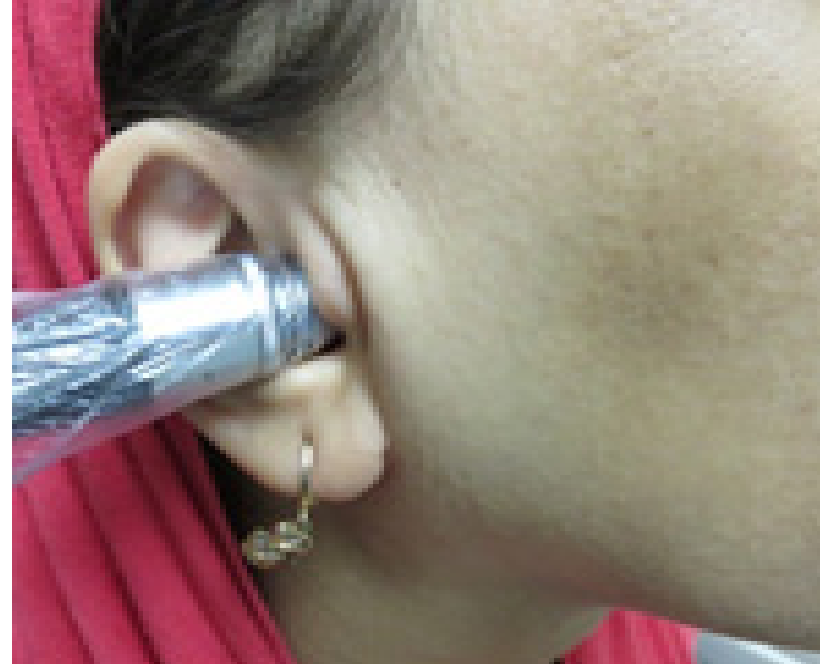

Fig 3: Application of laser probe on posterior aspect of the condyle from the external auditory meatus at rest position.

\section{RESULTS}

This study was conducted on thirty six patients thirty patients were females $(83.33 \%)$ and six patients were males $(16.66 \%)$. Mean age was $(26.58 \pm 6.83)$. There were no significant differences among both study groups in age $(P=0.837)$ or gender distribution $(P=0.439)$.

Assessment of pain level by VAS and MMO for all patients in Arthrocentesis group revealed a statistical significant reduction of pain and increase in MMO between preoperative and all postoperative records till 6 months $(P \leq 0.001)$. (Tables1,2)

In LLLT group, there was no significant difference at immediate postoperative. VAS was reduced significantly after $1^{\text {st }}$ week $(P \leq 0.002)$ then it was reduced gradually whereas the highest significant reduction in pain score was obvious at $4^{\text {th }}$ week, $3^{\text {rd }}$ month $6^{\text {th }}$ month results $(P \leq 0.001)$. A mild improvement in $\mathrm{MMO}$ was observed after $1^{\text {st }}$ week (0.63 $\mathrm{mm} \pm 0.89) P=0.007$. The significant change was observed after 2 nd and increased gradually until the 6th month.(Tables 1,2)

Comparison between both study groups after initial assessment revealed that there was a significant difference $(P \leq 0.001)$ in VAS in arthrocentesis group at postoperative, $1^{\text {st }}$ week and $2^{\text {nd }}$ while there was no significant difference was observed after $4^{\text {th }}$ week, $3^{\text {rd }}$ month and $6^{\text {th }}$ month. (Table 1, Fig.4).

The change in MMO was higher in arthrocentesis group than LLLT group. It was significant along all study $(P \leq 0.001)$. (Table 3, Fig 5)

Assessment of joint clicking sound denoted that in arthrocentesis group the clicking sound was disappeared immediately postoperative in all joints that presented with 
clicking preoperatively $(0.0 \%)$ at $6^{\text {th }}$ month it was denoted two cases presented with clicking in comparison to eight cases preoperatively. In LLLT group, the clicking sound was reduced in two cases at the end of the $2^{\text {nd }}$ week and after $6^{\text {th }}$ month it was reduced in six cases. In comparison between both groups a significant difference was observed in arthrocentesis group at immediate postoperative records only. (Table 4).

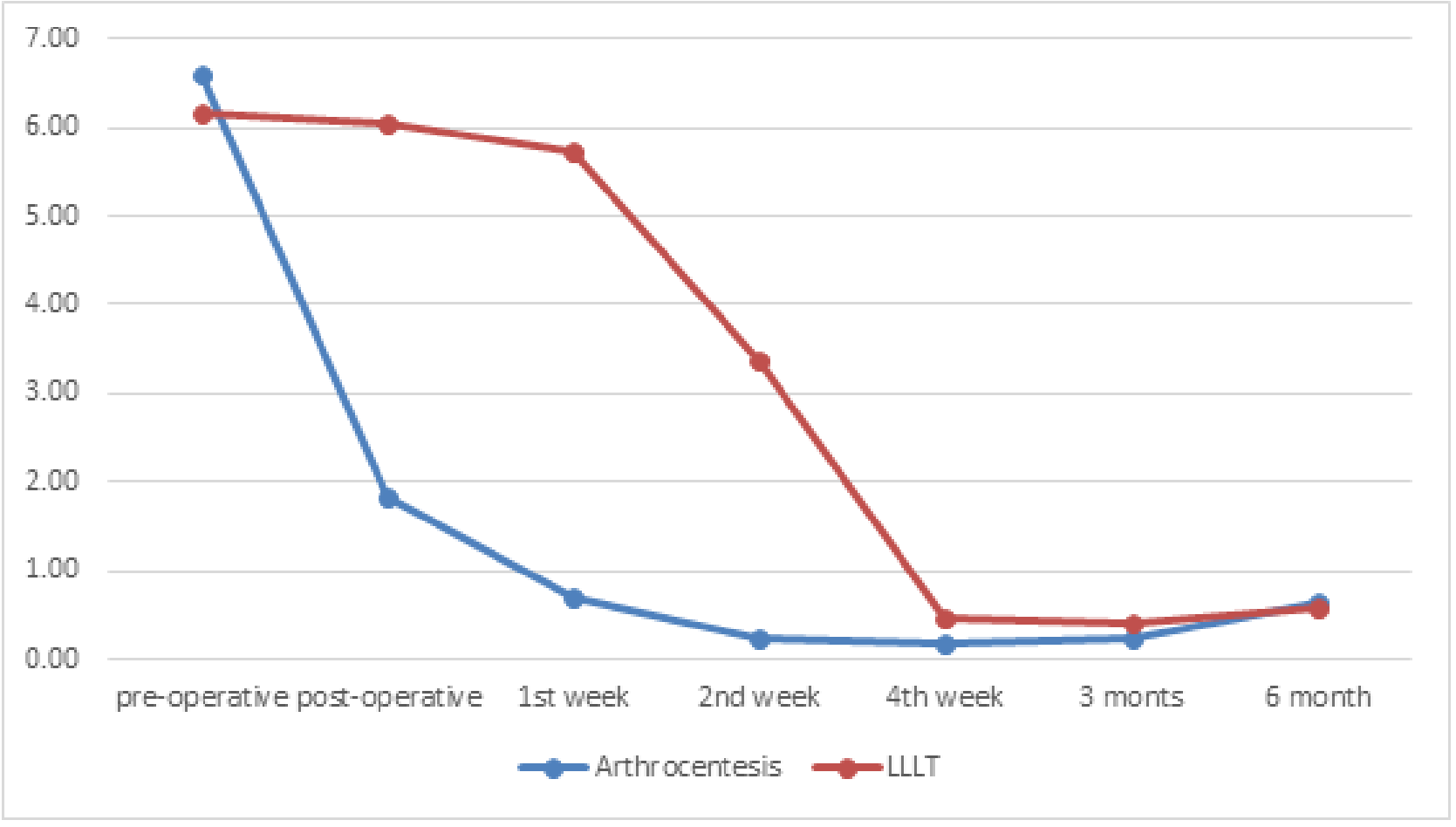

Fig 4 :Graph showing Pain VAS for both groups.

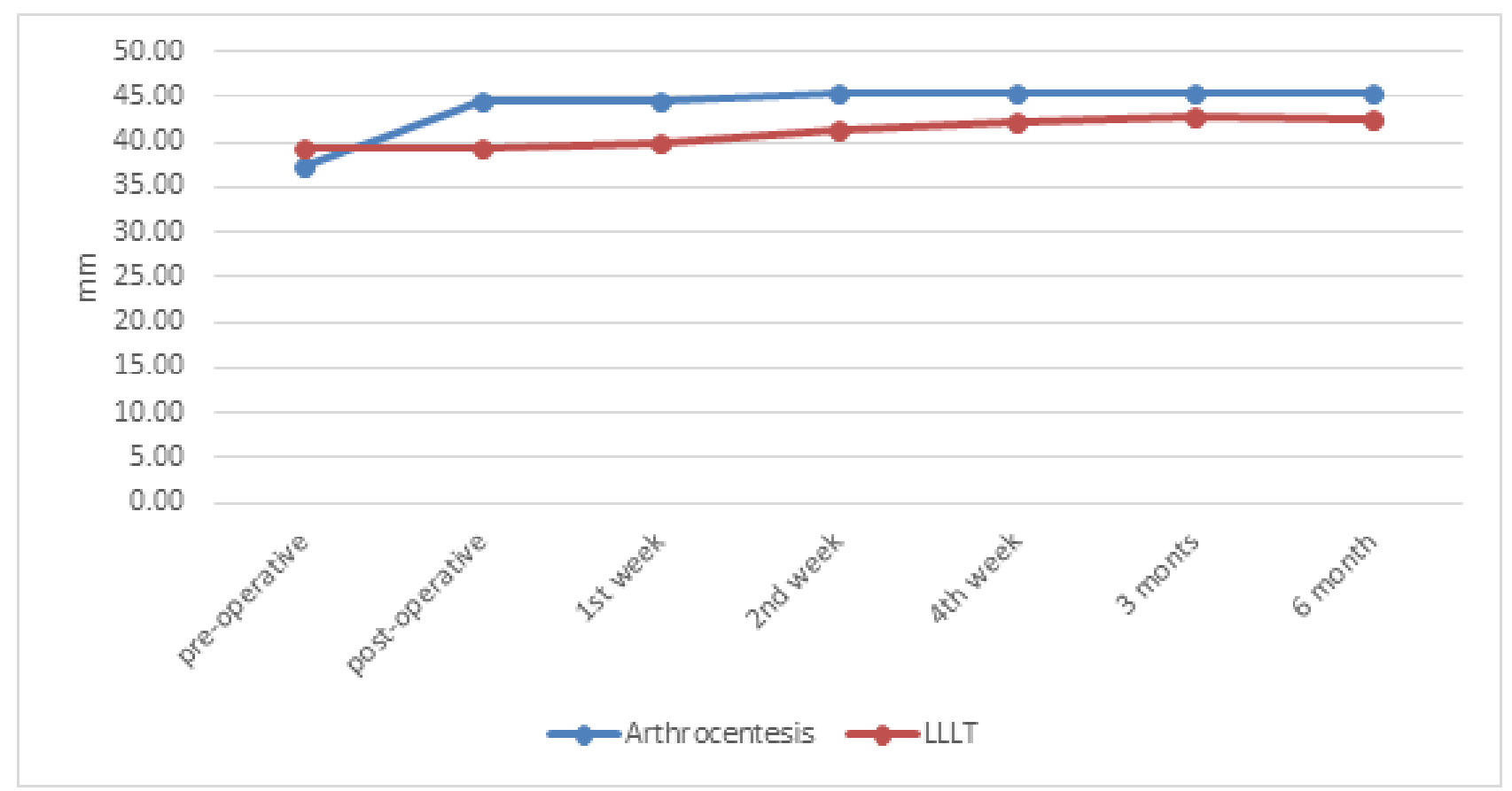

Fig 5 : Graph showing MMO for both groups 
Table 1 : Mean and SD of Pain VAS for tested groups

\begin{tabular}{|c|c|c|c|c|c|}
\hline \multirow{3}{*}{ VAS } & \multicolumn{4}{|c|}{ Group } & \multirow{3}{*}{ p-value } \\
\hline & \multicolumn{2}{|c|}{ Arthrocentesis } & \multicolumn{2}{|c|}{ LLLT } & \\
\hline & Mean & SD & Mean & SD & \\
\hline pre-operative & 6.59 & 1.06 & 6.16 & 1.12 & $0.300 \mathrm{NS}$ \\
\hline post-operative & 1.82 & .95 & 6.05 & 1.03 & $\leq 0.001 *$ \\
\hline p-value & $\leq 0.001^{*}$ & & $0.163 \mathrm{~N}$ & & \\
\hline $1^{\text {st }}$ week & .71 & .92 & 5.74 & 1.33 & $\leq 0.001^{*}$ \\
\hline p-value & $\leq 0.001 *$ & & $\leq 0.002$ & & \\
\hline $2^{\text {nd }}$ week & .24 & .44 & 3.37 & 1.07 & $\leq 0.001^{*}$ \\
\hline p-value & $\leq 0.001 *$ & & $\leq 0.001$ & & \\
\hline $4^{\text {th }}$ week & .18 & .39 & .47 & .61 & $0.196 \mathrm{NS}$ \\
\hline p-value & $\leq 0.001^{*}$ & & $\leq 0.001$ & & \\
\hline 3 months & .24 & .44 & .42 & .61 & $0.471 \mathrm{NS}$ \\
\hline p-value & $\leq 0.001 *$ & & $\leq 0.001$ & & \\
\hline 6 month & .65 & .93 & .58 & .77 & $0.975 \mathrm{NS}$ \\
\hline p-value & $\leq 0.001^{*}$ & & $\leq 0.001$ & & \\
\hline
\end{tabular}

*significance is considered at $p \leq 0.05$

Table 2: Mean and SD of the change in MMO for both groups

\begin{tabular}{|c|c|c|c|c|c|}
\hline \multirow[t]{2}{*}{ MMO } & & \multicolumn{3}{|c|}{ Paired Differences } & \multirow{2}{*}{ p-value } \\
\hline & & Mean & Std. Deviation & & \\
\hline \multirow{6}{*}{$\begin{array}{c}\text { Arthrocentesis } \\
\text { Group }\end{array}$} & $\begin{array}{l}\text { pre-operative - } \\
\text { post-operative }\end{array}$ & -7.35 & 3.21988 & -9.416 & $\leq 0.001 *$ \\
\hline & $\begin{array}{l}\text { pre-operative } \\
-1^{\text {st }} \text { week }\end{array}$ & -7.41 & 3.12368 & -9.783 & $\leq 0.001 *$ \\
\hline & $\begin{array}{l}\text { pre-operative } \\
-2^{\text {nd }} \text { week }\end{array}$ & -8.29 & 3.27423 & -10.444 & $\leq 0.001 *$ \\
\hline & $\begin{array}{l}\text { pre-operative } \\
-4^{\text {th }} \text { week }\end{array}$ & -8.29 & 3.27423 & -10.444 & $\leq 0.001 *$ \\
\hline & $\begin{array}{l}\text { pre-operative } \\
-3 \text { months }\end{array}$ & -8.29 & 3.27423 & -10.444 & $\leq 0.001 *$ \\
\hline & $\begin{array}{l}\text { pre-operative } \\
\text { - } 6 \text { months }\end{array}$ & -8.29 & 3.27423 & -10.444 & $\leq 0.001 *$ \\
\hline
\end{tabular}




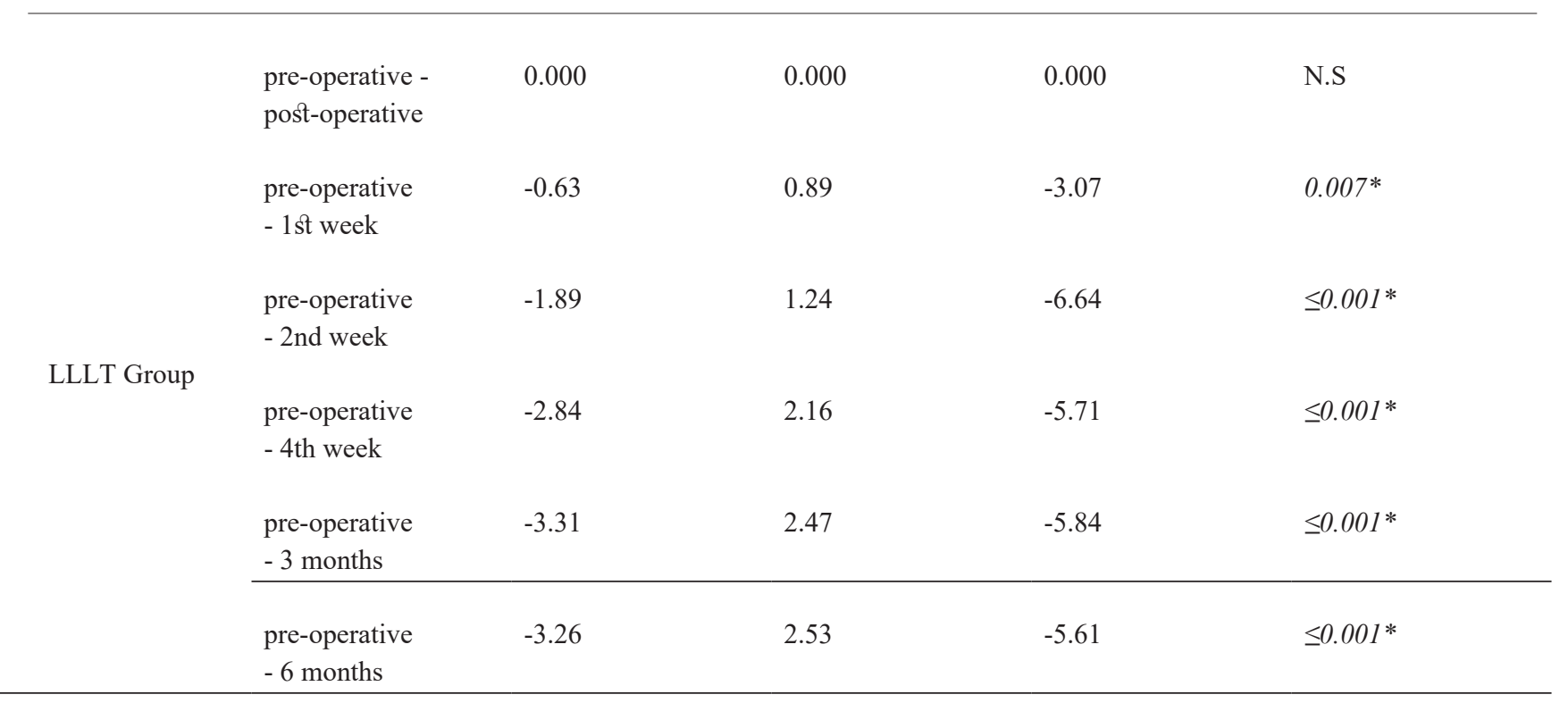

*significance is considered at $p \leq 0.05, \mathrm{NS}=$ Insignificant

Table 3 : Comparison in the change in MMO for both groups

\begin{tabular}{|c|c|c|c|c|c|}
\hline \multirow{3}{*}{ MMO } & \multicolumn{4}{|c|}{ Group } & \multirow{3}{*}{ p-value } \\
\hline & \multicolumn{2}{|c|}{ Arthrocentesis } & \multicolumn{2}{|c|}{ LLLT } & \\
\hline & Mean & SD & Mean & SD & \\
\hline post-operative & 7.35 & 3.22 & $0.00^{\mathrm{a}}$ & 0.00 & $\leq 0.001 *$ \\
\hline $1^{\text {st }}$ week & 7.41 & 3.12 & $.63^{\mathrm{b}}$ & .90 & $\leq 0.001 *$ \\
\hline $2^{\text {nd }}$ week & 8.29 & 3.27 & $1.89^{\mathrm{c}}$ & 1.24 & $\leq 0.001 *$ \\
\hline $4^{\text {th }}$ week & 8.29 & 3.27 & $2.84^{\mathrm{cd}}$ & 2.17 & $\leq 0.001 *$ \\
\hline 3 months & 8.29 & 3.27 & $3.32^{\mathrm{d}}$ & 2.47 & $\leq 0.001 *$ \\
\hline 6 months & 8.29 & 3.27 & $3.26^{\mathrm{d}}$ & 2.54 & $\leq 0.001 *$ \\
\hline
\end{tabular}

*significance is considered at $p \leq 0.05, \mathrm{NS}=$ Insignificant

Table 4: Frequency $(\mathrm{N})$ and Percentage (\%) of Clicking for different tested groups.

\begin{tabular}{|c|c|c|c|c|c|c|}
\hline & & \multicolumn{4}{|c|}{ Group } & \multirow{3}{*}{ p-value } \\
\hline \multicolumn{2}{|c|}{ Clicking } & \multicolumn{2}{|c|}{ Arthrocentesis } & \multicolumn{2}{|c|}{ LLLT } & \\
\hline & & $\mathrm{N}$ & $\%$ & $\mathrm{~N}$ & $\%$ & \\
\hline \multirow[t]{2}{*}{ pre-operative } & Yes & 8 & $47.1 \%$ & 8 & $42.1 \%$ & \multirow{2}{*}{$0.765 \mathrm{NS}$} \\
\hline & No & 9 & $52.9 \%$ & 11 & $57.9 \%$ & \\
\hline \multirow[t]{2}{*}{ post-operative } & Yes & 0 & $0.0 \%$ & 8 & $42.1 \%$ & \multirow[b]{2}{*}{$0.002 *$} \\
\hline & No & 17 & $100.0 \%$ & 11 & $57.9 \%$ & \\
\hline
\end{tabular}




\begin{tabular}{|c|c|c|c|c|c|c|}
\hline \multirow[b]{2}{*}{$1^{\text {st }}$ week } & Yes & 6 & $35.3 \%$ & 8 & $42.1 \%$ & $0.676 \mathrm{NS}$ \\
\hline & No & 11 & 6470 & 11 & & \\
\hline \multirow{3}{*}{$2^{\text {nd }}$ week } & Yes & 1 & $5.9 \%$ & 6 & $31.6 \%$ & $0.052 \mathrm{NS}$ \\
\hline & & & & & & \\
\hline & No & 16 & $94.1 \%$ & 13 & $68.4 \%$ & \\
\hline \multirow{3}{*}{$4^{\text {th }}$ week } & Yes & 2 & $11.8 \%$ & 1 & $5.3 \%$ & $0.481 \mathrm{NS}$ \\
\hline & & & & & & \\
\hline & No & 15 & $88.2 \%$ & 18 & $94.7 \%$ & \\
\hline \multirow{3}{*}{3 months } & Yes & 2 & $11.8 \%$ & 1 & $5.3 \%$ & $0.481 \mathrm{NS}$ \\
\hline & & & & & & \\
\hline & No & 15 & $88.2 \%$ & 18 & $94.7 \%$ & \\
\hline \multirow{3}{*}{6 months } & $\mathrm{w}$ & 2 & $11.8 \%$ & 2 & $10.5 \%$ & $0.906 \mathrm{NS}$ \\
\hline & & & & & & \\
\hline & No & 15 & $88.2 \%$ & 17 & $89.5 \%$ & \\
\hline
\end{tabular}

*significance is considered at $p \leq 0.05, \mathrm{NS}=$ Insignificant

\section{DISCUSSION}

In the current study, LLLT was applied in this study as a non-invasive single therapy in comparison with arthrocentesis for treatment of patients with TMJ ID. Arthrocentesis was selected for comparison as it was becoming an evident that arthrocentesis is a very good treatment method for internal derangement. This coincided with Monje et al, they reviewed twenty articles on arthrocentesis and they concluded that arthrocentesis is a simple, non-invasive, inexpensive and highly effective procedure, apart from having a low morbidity rate. They also suggested that arthrocentesis should be considered as an alternative to other more invasive TMJ surgical procedures, provided it is applied to selected groups of patients. ${ }^{[8]}$

Pain Visual analogue scale (VAS), maximal mouth opening and joint clicking were used as clinical parameters to evaluate efficacy of the treatment. In this study LLLT was applied on 3 points for ten session divided as three sessions per week .it was applied with the same parameters (870 nm wavelength in continuous mode at $75 \mathrm{~mW}$ for six minutes ) to every patient in each session. The results showed that the laser therapy improved the range of mouth opening and achieved a significant reduction of pain symptoms. Clinical studies of LLLT used on patients with disc derangement disorders used either AlGaAs 830 $\mathrm{nm}$ diode laser in continuous wave mode or $\mathrm{He} \mathrm{Ne}$ laser $632 \mathrm{~nm}$ combined with a diode laser $904 \mathrm{~nm}$ in pulsed mode have shown clinical benefits in terms of reduction in pain and clicking. Also, Mazzetto et al evaluated the effectiveness of low-level laser therapy LLLT on the improvement of the mandibular movements and painful symptoms in individuals with temporomandibular disorders using gallium-aluminum-arsenide laser (diode laser) with parameters ( $830 \mathrm{~nm}$ wavelength; $40 \mathrm{~mW}$ power output) for eight sessions two per week..$^{[10,17]}$

A Meta-analysis of Clinical Effects of Low-level Laser Therapy on Temporo-mandibular Joint Pain was published in 2013 by Wen-Dien et al to investigate the analgesic effect of LLLT that was used to treat TMJ pain in articles describing randomized controlled trials. They concluded that: application of LLLT to the masticatory muscle or joint capsule of the TMJ had a moderate analgesic effect. The evidence from these articles suggested that the analgesia mechanism was possibly photobiomodulation that decreased the inflammatory factors. It also suggested that nerve stimulation via LLLT occurs that changes the activity of the masticatory muscle ${ }^{[19]}$

The results of comparison between LLLT group and arthrocentesis group indicated superiority of arthrocentesis in pain reduction in the first two weeks, after that the result of both groups were close to each other as there was no statistical significant difference up to 6th month. The action of laser beam on joint capsule and synovial membrane as its dependent on cellular activity and metabolism that need a time to take part and raise to be significant, however the action of arthrocentesis is somewhat mechanical and physical action. These results coincide with known biological action of laser as it was proved the biomodulatory, anti-inflammatory and analgesic effects on physiological, cellular and systemic responses in addition to acceleration of wound healing.

In current study both study groups presented a statistical significant improvement in $\mathrm{MMO}$; however in comparison 
between efficacy of LLLT and arthrocentesis on TMJ it was found that a statistical significant difference between both groups as it was observed superiority of arthrocentesis on improvement of mouth opening. Improvement of MMO in LLLT group may probably referred to decreasing pain, inflammation and effusion in the joint which enable the patients to move the joint in a wider range in addition to bio-stimulative, regenerative biological effect of low level laser on the cellular structure of the TMJ in reducing pain and inflammation that enhance the joint component to act within the physiological capability. These results coincide with Kulekcioglu et al., as they investigated the effectiveness of LLLT in the treatment of TMD and compared treatment effects in myogenic and arthrogenic cases. They observed significant reduction in pain in both treatment groups, and the number of tender points; maximal mouth opening and lateral jaw motion were significantly improved in the active treatment group compared with the placebo group. ${ }^{[21]}$

Similarly, Salmos et al investigated the effect lowlevel laser therapy (LLLT) in reduction of pain intensity and improvement of maximal mouth opening in Fiftyeight patients divided in two groups, 32 acute TMD $(<6$ months) and 26 patients with chronic TMD ( $>6$ months). Both groups had a significant pain intensity reduction and maximal mouth opening improvement after LLLT and they concluded that Low-level laser therapy can be considered as an alternative physical modality or supplementary approach for management of acute and chronic myogenic temporomandibular disorder; however, patients with acute disease are likely to have a better outcome. ${ }^{[22]}$

In contrast Venancio et al and Emshoff et al considered these changes were not highly significant. This contraversy in the results may be attributed to the multifactorial aspects of the disorder i.e arthrogenic, myogenic or degenerative etc. In addition laser parameters adjusted for the selected treatment plan and number of sessions. ${ }^{[23,24]}$

In the current study, all patients selected were suffering from internal derangement and it was excluded all patients with TMJ artheritis or Myogenic disorders. The superiority of arthrocentesis in immediate action in relieving pain and significant difference in its effect on mouth opening is referred to the mechanical and physical action of arthrocentesis as it is considered a minor surgical procedure. Lavage of the upper joint space reduces pain by removing inflammation mediators from the joint, increasing mandibular mobility by removing intra-articular adhesions, eliminating the negative pressure within the joint, recovering disc and fossa space, and improving disc mobility, which reduces the mechanical obstruction caused by the anterior position of the disc the results of arthrocentesis were in agreement with studies. ${ }^{[20,24,25]}$

Analysing results of clicking sound in study groups indicated beneficial effect of both treatment modalities in reducing clicking with no statistical significant difference between them. The effect of arthrocentesis in on the clicking sound has been reported in a lot of publication to reduce joint pain, improve function, and reduce clicking as the arthrocentesis is considered an evident method to treat TMJ disc derangement ${ }^{[26,27]}$

In comparison between two study groups in the current study it was denoted that there was no statistical significance between LLLT and arthrocentesis on clicking sound of temporomandibular joint except in the immediate postoperative results. The effect of laser on clicking may be attributed to its biological effect on synovial membrane and muscular attachment to the disc and capsule. Clinical studies of LLLT used on patients with disc derangement disorders using either AlGaAs $830 \mathrm{~nm}$ diode laser in continuous wave mode or He Ne laser $632 \mathrm{~nm}$ combined with a diode laser $904 \mathrm{~nm}$ in pulsed mode have shown clinical benefits in terms of reduction in pain and clicking. ${ }^{[6,10,21]}$

\section{CONCLUSION AND RECOMMENDATION}

Low level laser therapy is effective and competitive treatment for patients with temporomandibular joint internal derangement regarding pain and clicking. Further investigation regarding dosimetry and technique of LLLT may be useful to expand indications and efficacy of soft laser.

\section{CONFLICT OF INTEREST}

There are no conflicts of interest.

\section{REFERENCES}

1. Herb Kathleen, Sung Cho, and Marlind Alan Stiles,: Temporomandibular Joint Pain and Dysfunction. Current Pain and Headache Reports; 10: 408-414, 2006.

2. Jeffrey P. Okeson: Joint Intracapsular Disorders: Diagnostic and Nonsurgical Management Considerations.Dent Clin N Am.; 51 :85-103, 2007

3. Dimitroulis G. Temporomandibular disorders: a clinical update. BMJ.; 18: 317(7152):190-4.1998

4. Herve R, Serban T: Current recommendations for the diagnosis of temporomandibular joint disorders - review paper. Part two. Mædica ; 3(2):130-135, 2008.

5. Ucar M, Sarp Ü, Koca İ, Eroğlu S, Yetisgin A, Tutoglu A, Boyacı A.Effectiveness of a home exercise program in combination with ultrasound therapy for temporomandibular joint disorders. J Phys Ther Sci.;26(12):1847-9, 2014. 
6. Bertolucci, L. E \& Grey, T. Clinical analysis of midlaser versus placebo treatment of arthralgic TMJ degenerative joints. Cranio, 13(1):26-9, 1995.

7. Nitzan DW, Dolwick MF, Martinez GA. Temporomandibular joint arthrocentesis: A simplified treatment for severe, limited mouth opening. J Oral Maxillofac Surg; 49: 1163-67, 1991.

8. Monje-Gil F, Nitzan D, González-Garcia R.: Temporomandibular joint arthrocentesis. Review of the literature. Med Oral Patol Oral Cir Bucal.; 1:17(4): 575-81, 2012

9. Hammuda A, Hamed M.S., Elsharrawy E. A. and Elsholkamy M. A. Validity of Viscosupplementation with Arthrocentesis in Management Of Temporomandibular Joint Internal Derangement. J Am Sci;9(8):54-59. 2013

10. Khan, M.; Vijayalakshmi, K. R. \& Gupta, N. Low intensity laser therapy in disc derangement disorders of temporomandibular joint : A review article. Int. J. Odontostomat., 7(2):235-239, 2013.

11. Joseph S. Rosenshein : Laser Biostimulation : Photobioactivation ,a Modulation of Biologic Processes by Low-Intensity Laser Radiation . Lasers in Maxillofacial Surgery and Dentistry by Lewis Clayman \& Paul Kuo published by Thieme Medical publisher New York, chapter (15) 165-171, 1997

12. Pang P, Coluzzi D, Rechmann P, Swick M: Laser Energy in Oral Soft Tissue Applications. Journal of Laser Dentistry 20 (2);65-73,2012

13. Marcello Melis,; Massimiliano Di Giosia, Khalid H. Zawawi : Low Level Laser Therapy for the Treatment of Temporomandibular Disorders: Systematic Review of the Literature. The journal of craniomandibular practice, 30 (4); 1-9, 2012.

14. Rahimi, A.; Rabier, S.; Mojadehi, S. M. \& Kosarieh, E. Application of low level lasers in temporomandibular disorders. J. Lasers Med. Sci., 2(4):165-70, 2011.

15. Inas S. M. Sayed, Ali Saafan, Fagr Kh. Abdel-Gawad2, Tarek A. Harhash, Mostapha A. Abdel-Rahman: Effect of low-level laser therapy on gene expression of vascular endothelial growth factor and interleukin-1 Bin scalpel-induced and laser-induced oral wounds in rats. Journal of Dental Lasers; 9(1),23-30, 2015.

16. Herranz-Aparicio J, Vázquez-Delgado E, ArnabatDomínguez J, España-Tost A, Gay-Escoda C.: The use of low level laser therapy in the treatment of temporomandibular joint disorders.
Review of the literature. Med Oral Patol Oral Cir Bucal. Jul 1;18(4), 603-12, 2013

17. Mazzetto M O, Hottat H, Pizzo R . Measurements of Jaw Movements and TMJ Pain Intensity in Patients Treated with Ga Al As Laser. Braz Dent $\mathrm{J} ; 21(4): 356-360,2010$

18. Manfredini D, Guarda-Nardini L, Winocur E, Piccotti F, Ahlberg J, Lobbezoo F : Research diagnostic criteria for temporomandibular disorders: a systematic review of axis I epidemiologic findings. Oral Surg Oral Med Oral Pathol Oral Radiol Endod. ;112(4):453-62, 2011.

19. Wen-Dien Chang, Chia-Lun Lee, Hung-Yu Lin, Yung-Chun Hsu, Chung-Jieh Wang, Ping-Tung Lai A Meta-analysis of Clinical Effects of Low-level Laser Therapy on Temporomandibular Joint Pain.J Phys Ther Sci. 2014 August; 26(8): 1297-1300.

20. Bhargava D, Jain M, Deshpande A, Singh A, Jaiswal $\mathrm{J}$ : Temporomandibular joint arthrocentesis for internal derangement with disc displacement without reduction. J Maxillofac Oral Surg.14(2):454-9. 2015

21. Kulekcioglu S, Sivrioglu K, Ozcan O, Parlak M. Effectiveness of low-level laser therapy in temporomandibular disorder. Scand J Rheumatol ;32:114-118. 2003

22. Salmos-Brito JA1, de Menezes RF, Teixeira CE, Gonzaga RK, Rodrigues BH, Braz R, Bessa-Nogueira RV, Gerbi ME.Evaluation of low-level laser therapy in patients with acute and chronic temporomandibular disorders. Lasers Med Sci.;28(1):57-64. 2013

23. Venancio Rde A, Camparis CM, Lizarelli Rde F. Low intensity laser therapy in the treatment of temporomandibular disorders: a double-blind study. J Oral Rehabil.; 32,800-807. 2005

24. Singh S, Varghese D. Single puncture arthrocentesis of temporomandibular joint; introducing a novel device: A pilot study . Nat J Maxillofac Surg. 2013;4(2):1937.

25. Malik AH1, Shah AA1 Efficacy of Temporomandibular Joint Arthrocentesis on Mouth Opening and Pain in the Treatment of Internal Derangement of TMJ-A Clinical Study. J Maxillofac Oral Surg.;13(3):244-8. 2014

26. Yoda T, Imai H, Shinjyo Y, Sakamoto I, Abe M, Enomoto S.: Effect of arthrocentesis on TMJ disturbance of mouth closure with loud clicking: a preliminary study. Cranio. ; 20(1):18-22. 2002

27. Tozoglu S1, Al-Belasy FA, Dolwick MF. A review of techniques of lysis and lavage of the TMJ.Br J Oral Maxillofac Surg.; 49(4):302-9. 2011 